Motrivivência $\quad$ v. $28, \quad$ n. $47, \quad$ p. $261-277$, maio/2016

\title{
DISCUSSÃO DE GÊNERO NAS AULAS DE EDUCAÇÃO FíSICA: uma revisão sistemática
}

\author{
Naiara da Rocha Matos \\ Geisa Silva Brasileiro² \\ Rodolfo Teixeira Rocha ${ }^{3}$ \\ Jorge Lopes Cavalcante Neto 4
}

\section{RESUMO}

O objetivo do presente estudo foi verificar por meio de revisão sistemática as implicações da possível participação ou/não participação das meninas nas aulas de Educação Física Escolar. Trata-se de um artigo de revisão sistemática realizado nas bases de dados do Portal de Periódicos CAPES e do Lilacs, e nas revistas científicas Motrivivência e Educação Física em Revista. Inicialmente foi encontrado um total de 260 artigos, no qual foram analisados minuciosamente os títulos, resumos, e posteriormente o artigo na íntegra, sendo selecionados apenas 07 artigos. Portanto, observou-se nos artigos selecionados uma forte influência construída historicamente e enraizada na sociedade sobre a participação das meninas nas aulas de Educação Física, estas são consideradas menos habilidosas para a prática esportiva quando comparadas aos meninos, e a sociedade, assim como a escola acabam por reforçar mais ainda essa superioridade masculina.

Palavras-chave: Gênero; Educação Física; Escola

Graduanda em Educação Física. UNEB. Salvador/Bahia, Brasil. E-mail: rocha.girls@hotmail.com

Graduanda em Educação Física. UNEB. Salvador/Bahia, Brasil. E-mail: geisabrasileira@hotmail.com

Graduando em Educação Física. UNEB. Salvador/Bahia, Brasil. E-mail: dolfometalico@hotmail.com

4 Doutorando em Fisioterapia - UFSCAR. Professor do curso de Educação Física da UNEB. Salvador/Bahia,

Brasil. E-mail: jorgelcneto@hotmail.com 


\section{INTRODUÇÃO}

Percebe-se que há grande diferença nas relações de gênero na sociedade, diferenças estas fruto de uma construção cultural que se perpetua até os dias de hoje. Sendo comprovado por Cruz e Palmeira (2009) ao afirmarem que historicamente as mulheres sempre exerceram papéis secundários em quaisquer setores da sociedade em comparação aos homens, e que essa relação estabelecida de superioridade masculina continua sendo reforçada por muitos professores em suas aulas, deixando transparecer os estereótipos e os preconceitos de gênero.

Para Campos et al. (2008) vivemos em uma sociedade marcada por exclusões, dentre as quais destaca-se a questão de gênero, entendido como a construção social que uma dada cultura estabelece ou elege em relação a homens e mulheres, bem como uma categoria sexual socialmente construída como nos asseguram Silva, Gomes e Queirós (2006).

Assim, percebe-se que existe um tratamento diferenciado dos meninos em relação a meninas, e a disciplina de Educação Física muitas vezes ainda auxilia na consolidação de conceitos equivocados, e torna-se um espaço propício para a manutenção de estereótipos, pois há incutido na sua cultura a pseudo-superioridade masculina, pelo fato dos meninos apresentarem uma maior desenvoltura no desenvolvimento de atividades físicas, haja vista que estes possuem um maior repertório motor, em consequência do maior número de vivências realizadas desde a infância (CRUZ; PALMEIRA, 2009).

Deste modo, de acordo com Nogueira e Rodrigues (2008) a Educação Física é uma disciplina que na escola diferencia-se das demais do currículo escolar quanto à formação de turmas, pois tem-se verificado a separação dos alunos por gêneros masculino e feminino, assim, compreende-se essa atitude como segregadora e discriminatória, na medida que continua reproduzindo os preconceitos ainda vigentes na sociedade. Portanto, Altmann, Ayoub e Amaral (2011) asseguram que durante algum tempo essa separação e diferenças eram consideradas inatas e decorrentes de razões biológicas, entretanto, pesquisas sobre o gênero contribuíram para compreender que elas são histórica e socialmente construídas.

Pesquisas (CAMPOS et al., 2008; NOGUEIRA; RODRIGUES, 2008; CRUZ; PALMEIRA, 2009) têm apontado que a escola enquanto formadora desta sociedade vem contribuindo para que perdure uma divisão sexista, permitindo a transmissão de valores de descriminação, colaborando de forma direta com essa triste realidade, não atuando, na maioria das vezes, como intermediadora para transformá-la. Dessa forma, nota-se nas aulas de Educação Física a separação ou mesmo a exclusão das meninas nas atividades, muitas vezes pautado no argumento de que estas possuem menos habilidades e força do que os meninos.

Em um estudo realizado por Altmann, Ayoub e Amaral (2011) sobre as relações de gênero nas aulas de Educação física, comprovou-se que está presente no discurso de alguns professores a concepção de que os meninos são mais habilidosos para a prática esportiva e para jogos coletivos, enquanto grande parte das meninas não se envolve com a mesma intensidade nessas práticas, pois não desejam suar e querem manter-se arrumadas. Contudo, no decorrer de seu estudo, os autores alertam que essa concepção é tida como concepções 
estereotipadas do feminino e do masculino, pois nem todos os meninos se identificam com esportes e jogos coletivos e que meninas também sabem e gostam de jogar.

De acordo com Resende (2008) a superação das desigualdades de gênero implica em mudança nas estruturas simbólicas que compõe as relações de poder entre homens e mulheres, então, deve-se pensar nas diferenças por outra perspectiva, repensar tais categorias de gênero não como naturais e imutáveis como sugere o discurso médico/biológico, mas como características construídas historicamente e, por isso, passíveis de mudanças e re-significações.

Portanto, Nogueira e Rodrigues (2008) advertem que a disciplina de Educação Física através de suas aulas, permanece reproduzindo uma educação sexista na medida em que os professores continuam a basear-se no gênero para formar turmas, reforçando os papéis sexuais na escolha de atividades "próprias" para meninos e meninas, separando assim, equipes masculinas e femininas nas competições escolares. Comprova-se a necessidade de novas discussões acerca deste assunto, pois a escolha dos professores de Educação Física, no que se refere à formação de turmas, não deve diferenciar-se, mas juntar-se a de todos os outros professores na construção de uma escola realmente democrática.

Tendo em vista os argumentos até aqui expostos, este estudo tem como objetivo geral verificar por meio de revisão sistemática as implicações da possível participação ou/não participação das meninas nas aulas de Educação Física Escolar.

\section{MÉTODOS}

Trata-se de um estudo de revisão sistemática realizada no período de 17 a 19 de março de 2015, nas bases de dados do Portal de Periódicos CAPES e do Lilacs, e nas revistas científicas Motrivivência e Educação Física em Revista. Utilizaram-se os seguintes descritores: Gênero, Educação Física e Escola, ambos retirados da base do Thesaurus Brasileiro da Educação do INEP (Instituto Nacional de Estudos e Pesquisas Educacionais Anísio Teixeira). Além disso, foram utilizados na busca pelos resultados os indicadores booleanos, especificamente o AND, usando como combinações os descritores Gênero and Educação Física and Escola.

Como critérios de inclusão, foram aceitos somente artigos originais, realizado com seres humanos, disponíveis na integra de forma gratuita, publicados nos últimos dez anos, e que fossem na língua portuguesa ou inglesa. Na busca inicial, utilizando os filtros foram encontrados 260 artigos, após a leitura dos títulos foram selecionados 10 artigos, após a leitura dos resumos/abstracts restaram 07 artigos e após a leitura dos textos na integra continuaram 07 artigos sendo, a amostra final. Todo o processo de sistematização das buscas em todas as bases de dados está ilustrado no organograma a seguir, figura 01 : 


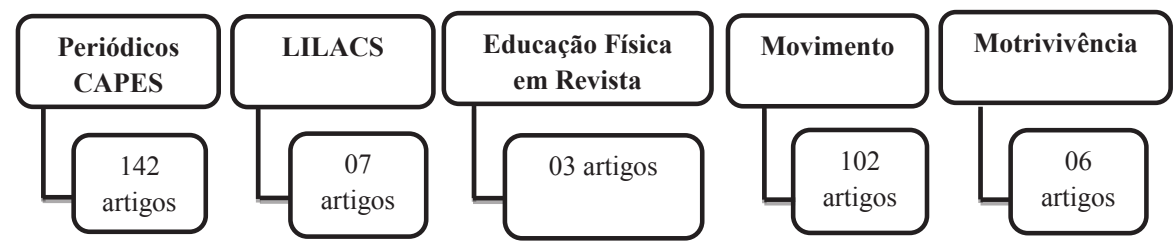

Figura 1 - Organograma das buscas nas bases de dados e nas revistas científicas Fonte: Próprio Autor (2015)

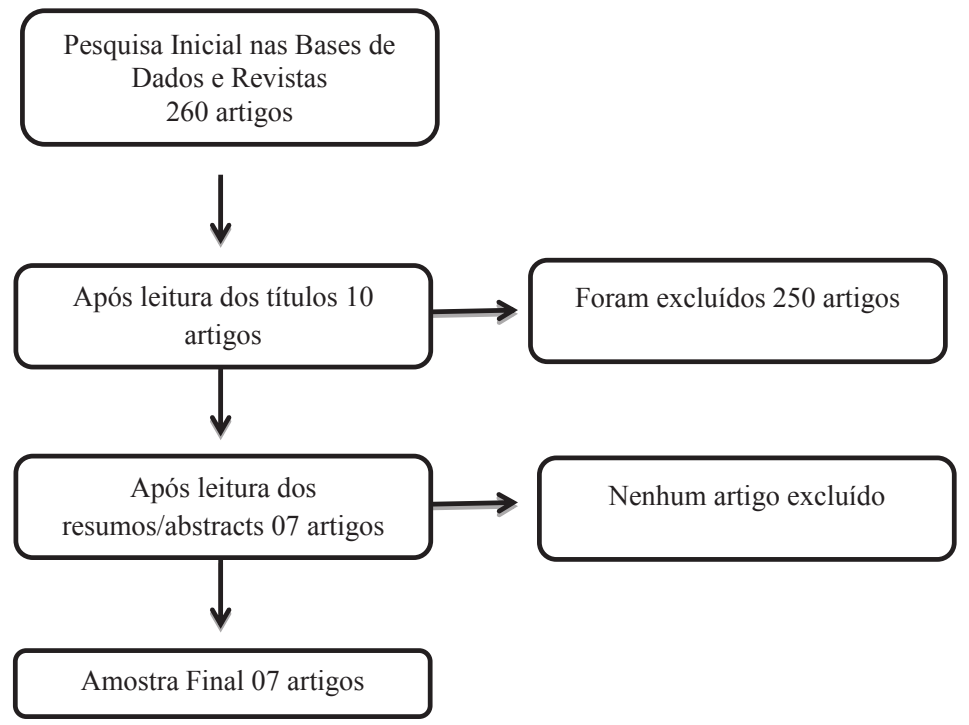

Figura 2 - Organograma de sistematização das buscas nas bases de dados e nas revistas científicas Fonte: Próprio Autor (2015)

\section{RESULTADOS E DISCUSSÃO}

A amostra final desta pesquisa foi composta por 07 artigos que foram localizados nas bases de dados e nas revistas selecionadas para o estudo.

O quadro 01 apresenta os principais achados dos estudos revisados neste artigo. 
V. $28, n^{\circ} 47$, maio/2016

\begin{tabular}{|c|c|c|}
\hline 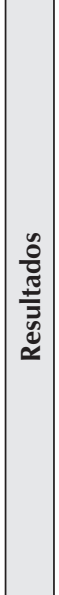 & 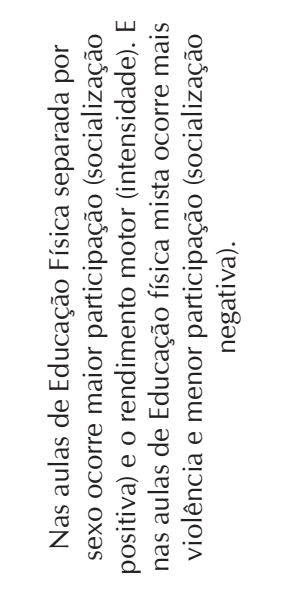 & 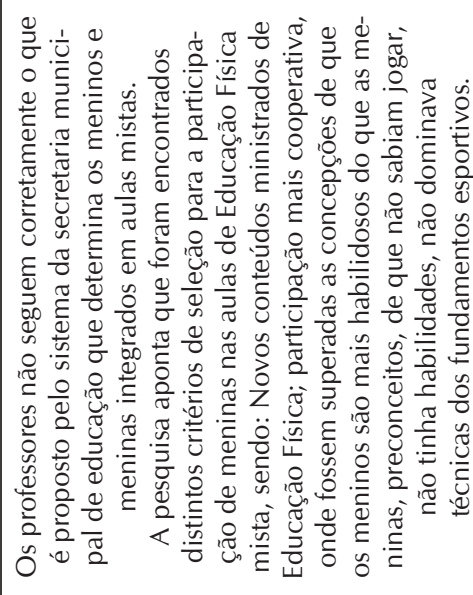 \\
\hline $\begin{array}{l}\frac{0}{0} \\
\frac{0}{0} \\
\frac{0}{2} \\
\end{array}$ & 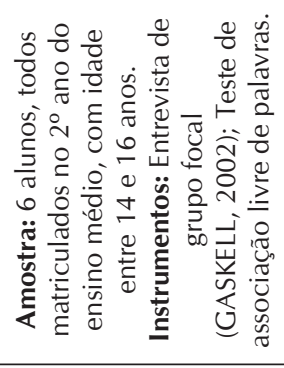 & 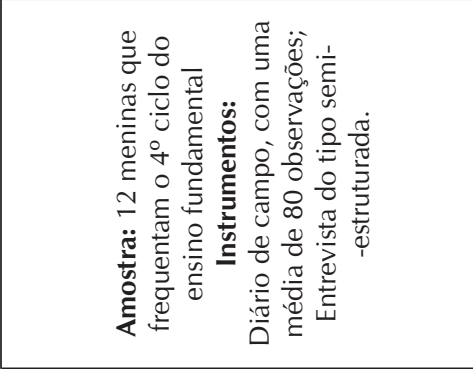 \\
\hline $\begin{array}{l}\bar{\Xi} \\
\vdots \\
\vdots \\
0 \\
\vdots \\
\dot{\delta}\end{array}$ & 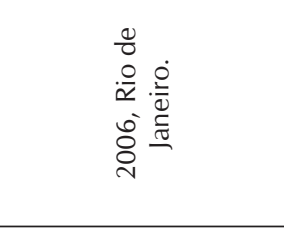 & 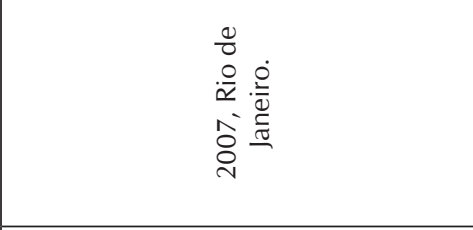 \\
\hline 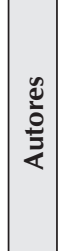 & 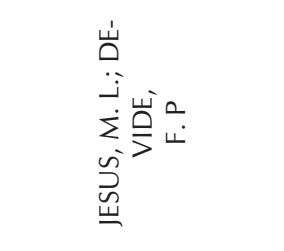 & 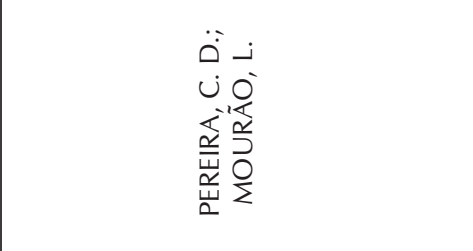 \\
\hline$\frac{0}{\underline{\Xi}}$ & 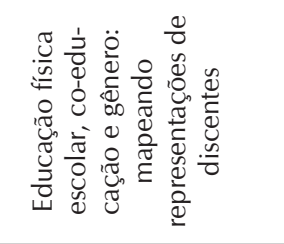 & 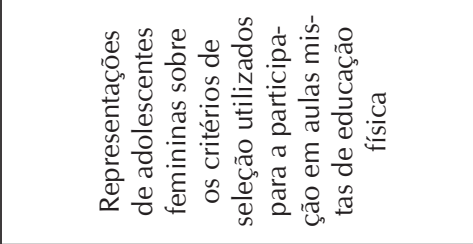 \\
\hline
\end{tabular}




\begin{tabular}{|c|c|c|}
\hline & 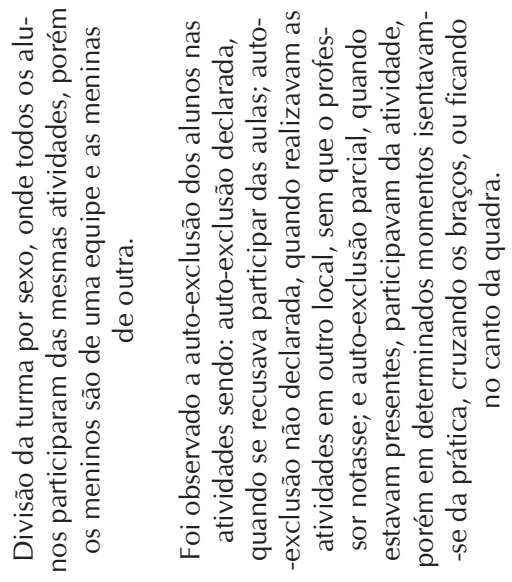 & 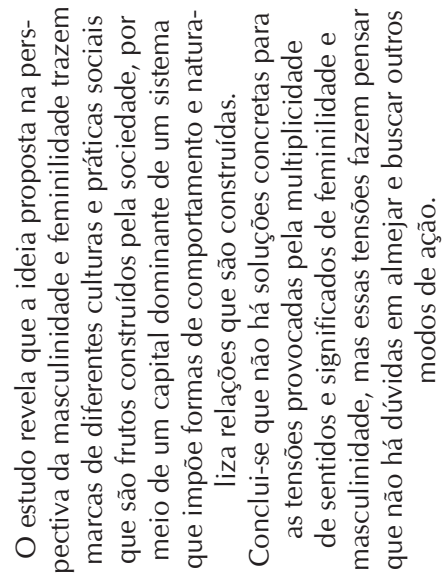 \\
\hline $\begin{array}{l}\frac{0}{0} \\
\frac{0}{0} \\
\frac{0}{2}\end{array}$ & 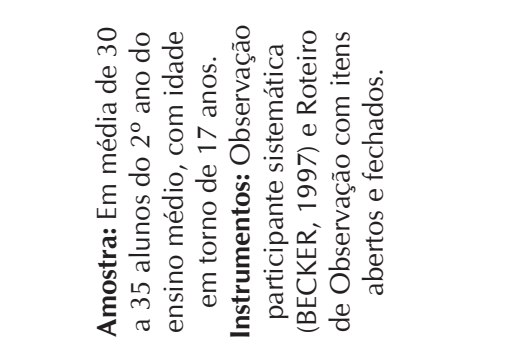 & 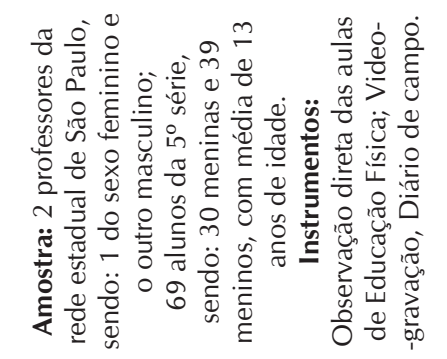 \\
\hline 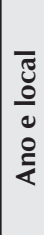 & 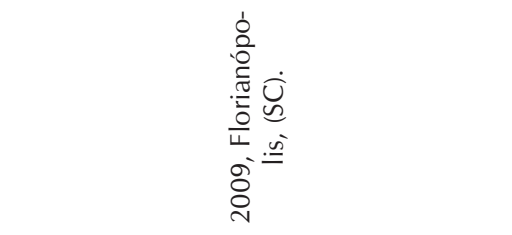 & $\frac{\stackrel{n}{n}}{O^{-}}$ \\
\hline 造 & 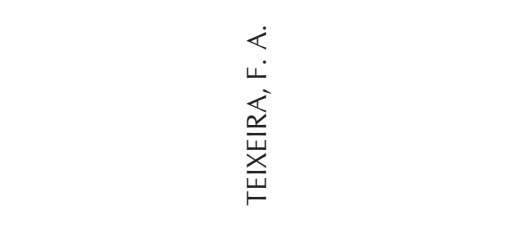 & 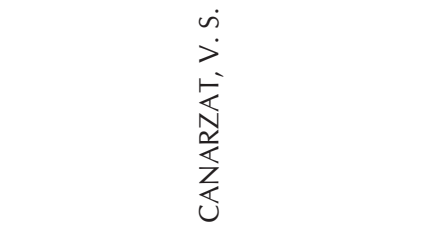 \\
\hline 足 & 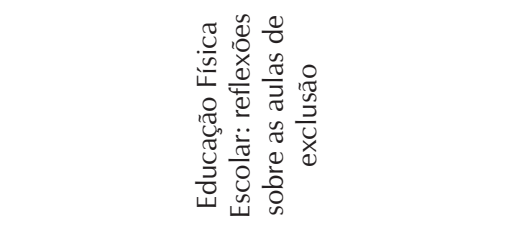 & 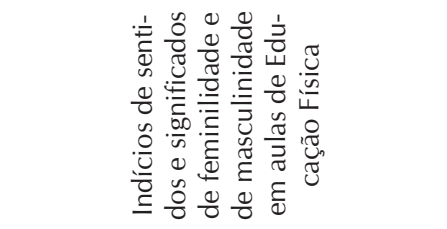 \\
\hline
\end{tabular}


V. $28, n^{\circ} 47$, maio/2016

\begin{tabular}{|c|c|c|c|}
\hline & 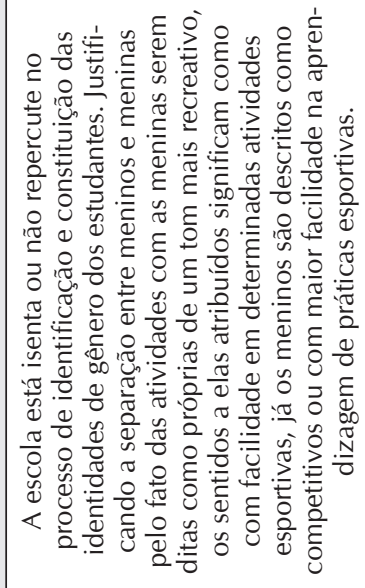 & 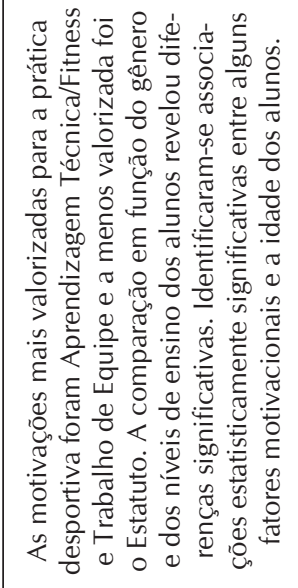 & 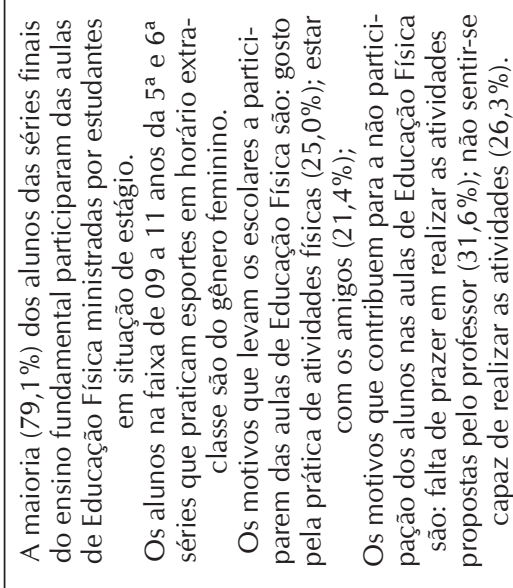 \\
\hline $\mid \begin{array}{l}\frac{\mathscr{0}}{0} \\
\frac{0}{20} \\
\frac{0}{2}\end{array}$ & 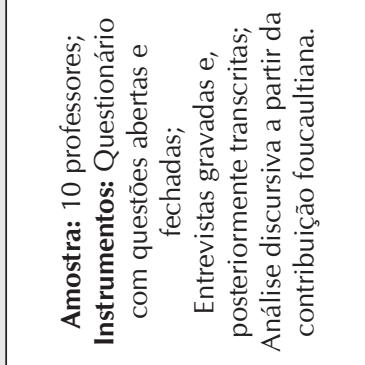 & 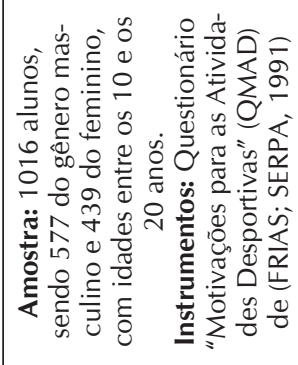 & 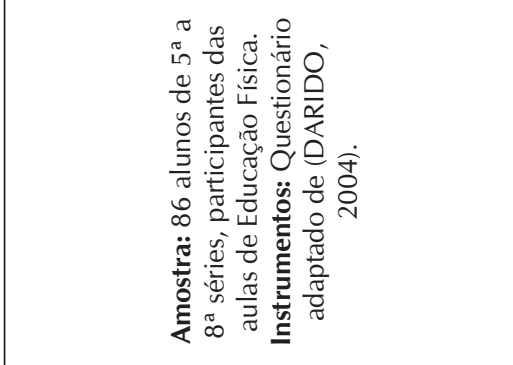 \\
\hline 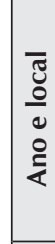 & 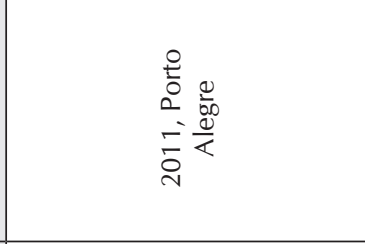 & 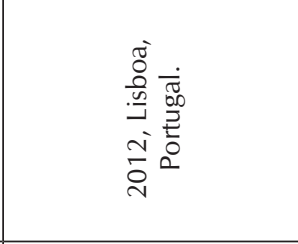 & 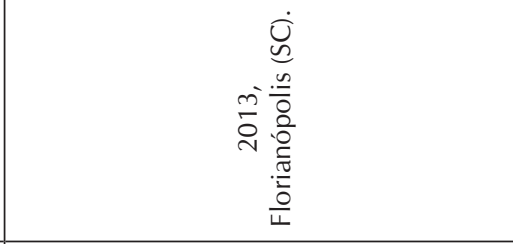 \\
\hline 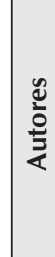 & 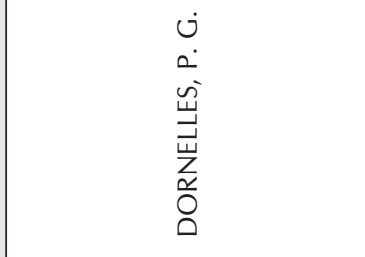 & 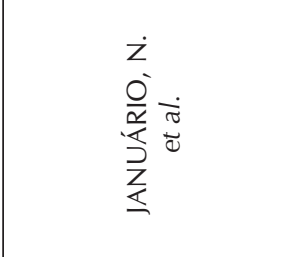 & 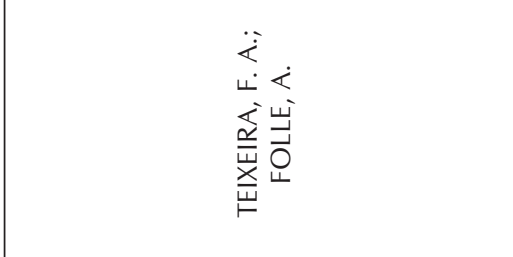 \\
\hline 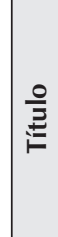 & 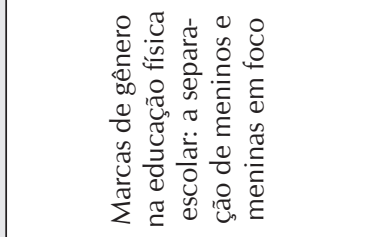 & 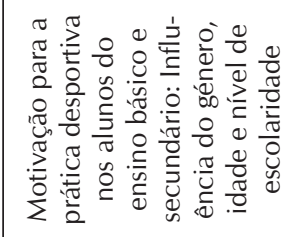 & 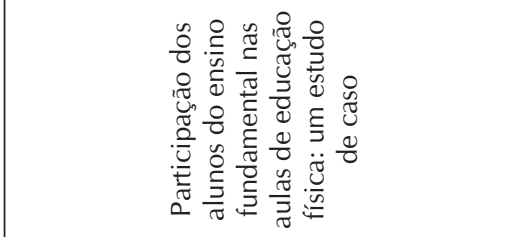 \\
\hline
\end{tabular}


Pode-se observar que dentre os 07 artigos selecionados nas bases de dados e nas revistas científicas, 03 são procedentes da Região Sudeste do Brasil, 03 da Região Sul do Brasil e apenas 01 do Sul da Europa. Sendo pesquisas oriundas de Cursos de Graduação e Programas de Pós-Graduação. São produções realizadas em Universidades e Faculdades de duas regiões brasileiras e também do Continente Europeu. Assim, em relação às duas regiões brasileiras, Ferreira e Grahl (s.d) consideram a Região Sudeste a região mais populosa, rica e desenvolvida do Brasil, onde se concentra um número muito significativo de Universidades, mais de 60 Universidades Públicas e Privadas e abriga os três maiores pólos de pesquisa e desenvolvimento do Brasil, representados pelas cidades de São Paulo, Rio de Janeiro e Campinas.

Portanto, apesar do número de pesquisas selecionadas para o estudo, serem as mesmas nas duas regiões brasileiras, percebe-se através do estudo de Sidone (2013) que a Região Sudeste se destaca em comparação a Região Sul, tendo em vista que há concentração de atividades científicas nesta região, possui centros e institutos de pesquisas consolidados, com alto nível de atividades e produções e também sedia as maiores Universidades Públicas Estaduais e Federais do país, a exemplo de São Paulo (USP, Unifesp, UNICAMP) e Rio de Janeiro (UFRJ, UERJ).

Em relação às amostras dos estudos, verificou-se que houve uma disparidade no quantitativo dos sujeitos, uma vez que em nenhum dos artigos relacionados, as amostras dos sujeitos participantes foram as mesmas. A maior amostra foi de 1016 alunos, sendo 577 do gênero masculino e 439 do feminino, com idades entre 10 e
20 anos da cidade de Lisboa (JANUÁRIO et al., 2012), e a menor amostra de 6 alunos, com idade entre 14 e 16 anos da cidade de Rio de Janeiro (JESUS, DEVIDE, 2006). Possivelmente a amostra de Januário et al., (2012) foi a maior no quantitativo de sujeitos, pelo fato dos referidos pesquisadores terem analisados alunos de dez escolas de Lisboa, cujos níveis de escolaridade eram 283 do segundo ciclo de escolaridade, 416 do terceiro ciclo de escolaridade e 317 do ensino secundário. Diferentemente do estudo de Jesus e Devide (2006) que analisou somente uma escola do Rio de Janeiro e uma série específica, o $2^{\circ}$ ano do ensino médio.

Assim, nos estudos selecionados, constatou-se uma heterogeneidade de instrumentos usados nas coletas de dados, dos sete artigos, apenas dois pesquisadores (JANUÁRIO et al., 2012; TEIXEIRA; FOLLE, 2013) optaram por utilizar somente um instrumento. Em contrapartida, os outros pesquisadores (JESUS, DEVIDE, 2006; PEREIRA, MOURÃO, 2007; TEIXEIRA, 2009; CANARZAT, 2010; DORNELLES, 2011) fizeram o uso de dois a três instrumentos divergentes.

Deste modo, notou-se que dos sete artigos, três pesquisadores (PEREIRA; MOURÃO, 2007; TEIXEIRA, 2009; CANARZAT, 2010) fizeram o uso da observação para coletar os dados, no entanto, dois deles especificaram que tipo de observação foi realizada. Assim, na concepção de Queiroz et al. (2007) a observação tornou-se uma técnica científica a partir do momento em que passa por sistematização, planejamento e controle da objetividade, não pode-se observar tudo e nem muitas coisas ao mesmo tempo, assim, uma das condições fundamentais de se observar 
adequadamente é limitar e definir com precisão os objetivos que se deseja alcançar, ou seja, exige uma sistematização prévia (roteiro de observação) que deve focar os objetivos da investigação.

Percebe-se por meio de Correia (2009) que a técnica da observação participante sistemática utilizada no estudo de Teixeira (2009) consiste no contato direto, frequente e prolongado do investigador, com os autores sociais, nos seus contextos culturais, onde o próprio investigador é instrumento de pesquisa, sendo um meio de investigação que deve ser planejada de modo sistemático, sujeita avaliação e verificação, precisão e controle.

Desta forma, Barbosa (1998) considera a observação direta utilizada no estudo de Canarzat (2010) como um método de coleta de dados que requer um sistema de pontuação muito bem preparado e definido, treinamento adequado dos observadores, supervisão durante aplicação e procedimentos de verificação periódica para determinar a qualidade das medidas realizadas.

Em relação às coletas de dados utilizadas no presente estudo, três estudiosos (DORNELLES, 2011; JANUÁRIO et al., 2012; TEIXEIRA; FOLLE, 2013) fizeram o uso do questionário, dois deles apontaram o tipo de questionário usado. Assim sendo, na visão de Chaer, Diniz e Ribeiro (2011) o questionário é uma técnica que permite coletar as informações da realidade, este pode conter questões abertas e fechadas. As perguntas abertas permitem liberdade ilimitada de respostas ao informante, nelas o respondente poderá utilizar sua linguagem própria, não havendo influência das respostas pré-estabelecidas pelo pesquisador, pois o informante escreverá aquilo que the vier à mente. Já as perguntas fechadas traz alternativas específicas para que o informante escolha uma delas, limitando assim, as possibilidades de respostas e restringindo a manifestação do interrogado.

Deste modo, Oliveira et al. (2010) afirmam que o questionário "Motivações para as Atividades Desportivas" (QMAD) utilizado no estudo de Januário et al. (2012) é composto por 30 itens que descrevem as razões para a atividade desportiva, os quais são agrupados em 7 subescalas: 1) Realização- estatuto; 2) Divertimento; 3) Atividade em grupo; 4) Contextual; 5) Aptidão Física; 6) Aperfeiçoamento técnico; 7) Influência de familiares e amigos. As respostas são dadas num continuum de 05 pontos que variam entre os extremos "Nada importante", que assume o valor 01 , até ao "Totalmente importante", com valor 05 .

Diferentemente do questionário QMAD, o questionário adaptado de Darido (2004) usado no estudo de Teixeira e Folle (2013) é composto segundo Teixeira e Moletta (2011) por 21 questões de múltipla escolha, o qual aborda quatro temas, dentre eles: caracterização dos sujeitos (idade, gênero, série); motivação/participação dos alunos na aula de Educação Física; aspectos culturais dos alunos e informações didáticas relacionadas às aulas de Educação Física.

No estudo, três pesquisadores (JESUS, DEVIDE, 2006; PEREIRA, MOURÃO, 2007; DORNELLES, 2011) utilizaram a entrevista para a coleta dos dados, apontando ainda o tipo de entrevista realizada. Assim, a entrevista é considerada por Martins e Bógus (2004) como um meio que permite o acesso a dados de difícil alcance por meio da observação direta, tais como sentimentos, pensamentos e intenções. Sua grande vantagem perante outras técnicas reside no fato que esta permite a captação imediata da informação desejada. 
Segundo Duarte (2004) a entrevista permite ao pesquisador fazer uma espécie de mergulho em profundidade, coletando indícios dos modos como cada um daqueles sujeitos percebe e significa sua realidade, levantando informações consistentes que Ihe permitam descrever e compreender a lógica que preside as relações que se estabelece no interior daquele grupo. Assim, Schraiber (1995) apud Belei et al.(2008) advertem que o uso de gravador, ou seja, a entrevista gravada realizada no estudo de Dornelles (2011) permite a ampliação do poder de registro e captação de elementos de comunicação de extrema importância, pausas de reflexão, dúvidas ou entonação da voz, aprimorando a compreensão da narrativa.

Além disso, a entrevista de grupo focal usada no estudo de Jesus e Devide, (2006) é descrita por Gomes e Barbosa (1999) como grupo de discussão informal e de tamanho reduzido, com a finalidade de obter informações de caráter qualitativo em profundidade, bem como é uma técnica rápida e de baixo custo, seu principal objetivo é desvendar as percepções dos participantes sobre determinados tópicos em discussão. Em concordância, Lervolino e Pelicioni (2001) asseguram que a essência do grupo focal consiste na interação entre os participantes e o pesquisador, que busca adquirir dados a partir da discussão focada em tópicos específicos e diretivos, sendo composto normalmente por 6 a 10 participantes que não são familiares uns aos outros.

A entrevista semi-estruturada usada no estudo de Pereira e Mourão (2007) pode ser compreendida na visão de Martins e Bógus (2004) como aquela que parte de certos questionamentos básicos, apoiados em teorias e hipóteses, que interessam à pesquisa e que oferecem amplo campo de interrogativas, fruto de novas hipóteses que vão surgindo à medida que se recebem as respostas do entrevistado.

No estudo realizado, dois pesquisadores (PEREIRA, MOURÃO, 2007; CANARZAT, 2010) fizeram o uso do diário de campo nas coletas dos dados. Martins e Bógus (2004) compreendem o diário de campo como uma forma de registro, que pode ser usado para planejar futuras observações, calcular custos e anotar o tempo que foi gasto. Nesta perspectiva, Neves (2006) entende o diário de campo como um instrumento onde se registram as observações, os acontecimentos ocorridos em campo e as impressões subjetivas decorridas destes acontecimentos, de forma mais minuciosa possível.

Observa-se no estudo ainda, que alguns estudiosos utilizaram outros instrumentos para coletar os dados como: O teste de associação livre de palavras (JESUS, DEVIDE, 2006), a vídeogravação (CANARZAT, 2010) e a análise discursiva (DORNELLES, 2011).

De tal modo, para Vieira e Coutinho (2008) o teste de associação livre de palavras consiste em um tipo de investigação aberta que se estrutura por meio da evocação de respostas dadas a partir de um ou mais estímulos indutores, estímulos estes que devem ser previamente definidos em função do objeto a ser pesquisado ou do objeto da representação, levando em consideração as características da amostra ou os sujeitos da pesquisa. Na visão de Tavares et al. (2014) esta técnica por meio de induções, consegue captar e receber informações, aparentemente ocultas ou não, e que através de uma resposta associativa a 
uma imagem ou a uma palavra é possível revelar as opiniões, os pensamentos e as personalidades.

Em relação à vídeogravação, Melo, Figueiredo e Nascimento (2003) advertem que é uma técnica que contribui para melhorar a precisão ou coerência com que o observador apreende o fenômeno, pois permite a exposição repetida do observador à mesma ocorrência do observado, bem como amplia a possibilidade do observador repensar o observado, ou seja, amplifica sua capacidade de análise.

Diferente dos outros instrumentos para a coleta dos dados, a análise discursiva na visão de Melo (2009) não trata de analisar somente a língua, mas o que há por meio dela, as relações de poder, a institucionalização de identidades sociais, os processos de inconsciência ideológica, enfim, diversas manifestações humanas. Assim, na perceptiva Fischer (2001) esse tipo de análise considera as relações históricas, as práticas concretas que estão vivas nos discursos, buscando antes de tudo tentar escapar da fácil interpretação daquilo que estaria por trás dos documentos, procurando explorar ao máximo os materiais.

De modo geral, observou-se em relação aos resultados dos artigos, que os dados apontam uma similaridade entre ambos, tendo em vista que sinalizam a separação das meninas e dos meninos nas aulas de Educação Física, alegando violência nas aulas mistas, menor socialização, a auto-exclusão por parte das meninas nas aulas práticas e também por considerar o sexo feminino fácil perante o sexo masculino, declarando que os meninos são mais habilidosos e que as meninas não sabem jogar, não têm habilidades e não dominam as técnicas e os fundamentos esportivos (JESUS,
DEVIDE, 2006; PEREIRA, MOURÃO, 2007; TEIXEIRA, 2009; CANARZAT, 2010; DORNELLES, 2011; TEIXEIRA; FOLLE, 2013).

Essa divisão por sexo nas aulas de Educação Física foi também comprovado por outras pesquisas, a exemplo de Cruz e Palmeira (2009) que tentou esclarecer os motivos que levam os professores a separar meninos de meninas, e confirmou que os professores utilizam argumentos pautados nas diferenças de habilidades e força existente entre gêneros. Do mesmo modo, Lima e Dinis (2007) advertem que as aulas de Educação Física acabam fortalecendo padrões e estereótipos de gênero, produzindo sujeitos masculinos e femininos, afirmando que existe o predomino de uma tradição biológica e tecnicista arraigada na história e nas práticas da Educação Física, sendo percebida nas atividades escolares, na quais prevalecem a prática desportiva e a divisão das atividades entre meninos e meninas.

Em concordância, Altmann, Ayoub e Amaral (2011) demonstram que as questões de gênero não são consensuais entre os professores de Educação Física, por um lado há docentes que defendem as vantagens e a importância de se trabalhar com turmas mistas, por outro lado, existem aqueles que defendem a separação, reafirmando a ideia, bastante corrente na área da educação, de que trabalhar com grupos 'homogêneos' facilitaria o desenvolvimento das aulas, reduzindo conflitos e tensões oriundos da diversidade das relações.

Observa-se nos resultados dos artigos analisados que os pesquisadores atribuem à sociedade a criação e propagação de conceitos equivocados em relação ao sexo masculino e feminino, pois há incutido no pensamento de muitas pessoas que os meninos têm fácil aprendizagem motora 
nas aulas práticas e são mais competitivos, e que as meninas preferem não participar da vivência por motivos de estética. Além disso, notou-se também que o gênero feminino apresenta valores menores na motivação para aprendizagem técnica e ao fitness quando comparados aos meninos (JESUS, DEVIDE, 2006; PEREIRA, MOURÃO, 2007; TEIXEIRA, 2009; CANARZAT, 2010; DORNELLES, 2011; JANUÁRIO et al., 2012; TEIXEIRA; FOLLE, 2013).

Portanto, verificou-se que em ambos os artigos, há maior participação do gênero masculino nas aulas de Educação Física quando confrontado com o gênero feminino, ou seja, existe uma diferenciação em função do gênero. E essa diferenciação como nos advertem Maia, Navarro e Maia (2011) são reforçadas pela escola e pelos professores ao afirmarem que as meninas em comparação aos meninos são incapazes na realização de atividades motoras. Contudo, notou-se também que mesmo existindo essa separação, pesquisadores (JESUS, DEVIDE, 2006) mostram nos artigos selecionados que há a possibilidade de amenizar essa situação, com a intervenção do docente nas atividades.

\section{CONCLUSÃO}

A partir dos achados nos artigos selecionados, conclui-se que as implicações da possível participação ou/não participação das meninas nas aulas de Educação Física Escolar, vem de longa data, são construídas e enraizadas historicamente, preconizadas pela sociedade, onde quem pratica esporte é apenas o gênero masculino, e que o sexo feminino estão apenas estabelecido em papéis secundários deixados, evidenciando a superioridade da força masculina. Sendo caracterizado como uma limitação, ou até uma barreira a ser vencida pela escola, pela Educação Física Escolar, para que ocorra a miscigenação da classe nas atividades escolares como um todo, e consequentemente maior participação das meninas.

Assim, de acordo com a história, a educação tem colaborado para essa perpetuação da estereotipia sexual, onde os preconceitos sexuais têm como base argumentos na ordem biológica, desencadeando numa diferença exacerbada de experiências vivenciadas por ambos os sexos, interferindo diretamente em sua vida na sociedade. Nesse sentido a evasão das meninas do esporte se repete, já que historicamente os meninos ocuparam o lugar privilegiado no esporte.

Outro ponto a ser discutido referente ao tema, é que para que aconteça uma participação significativa do gênero feminino nas aulas de Educação Física, é fundamental o papel do docente e da escola, que tem a função de estimular e motivar as meninas a aflorar o desejo de praticar atividade física de maneira prazerosa, desenvolvendo e esboçando aulas criativas no curso, onde fica comprovada o quanto é necessário a importância do professor e da instituição, em desenvolver métodos e estratégias no desenvolvimento de seus planos de aulas que ao elaborarem métodos e estratégias na aplicação e planejamento de suas aulas com conteúdos que serão abordados durante o ano com a finalidade de que se diminua o desinteresse e a evasão dos alunos nas aulas de Educação Física.

Enfim, este estudo não deve-se esgotar por aqui, desejamos que mais pesquisadores se engajem e adentrem nesta discussão, buscando estratégias que 
possibilite a ampliação do debate sobre a questão de gênero, principalmente no ambiente escolar, uma vez que a partir dos estudos realizados, notamos a carência e a necessidade de mais produções nessa área.

\section{REFERÊNCIAS}

ALTMANN, H.; AYOUB, E.; AMARAL, S. C. F. Gênero na prática docente em Educação Física: "meninas não gostam de suar, meninos são habilidosos ao jogar"? Estudos Feministas, Florianópolis, v. 19, n. 2, p. 491-501, maio/ago.2011. Disponível em: <https://periodicos. ufsc.br/index.php/ref/article/view/ S0104-026X2011000200012. Acesso em: 18 mar. 2015.

BARBOSA, E. F. Instrumentos de Coleta de Dados em Projetos Educacionais, Educativa- Instituto de Pesquisas e Inovações Educacionais, Belo Horizonte - MG, 1999. Disponível em: http:// www2.unifap.br/midias/files/2012/03/ coleta_dados.pdf. Acesso em: 12 ago. 2015.

BELEI, R. A. et al. O uso de entrevista, observação e vídeogravação em pesquisa qualitativa. Cadernos de Educação, Pelotas, v.30, p.187-199, jan./jun. 2008. Disponível em: http:// www.unisc.br/portal/upload/com arquivo/1350501221.pdf. Acesso em: 11 ago. 2015.

CAMPOS, A. F.et al. A questão de gênero nas aulas de Educação Física. Revista Brasileira de Educação Física, Esporte, Lazer e Dança, Santo André, v. 3, n. 3, p. 79-88, set. 2008. Disponível em: http://www.educadores.diaadia.pr.gov. br/arquivos/File/2010/artigos_teses/
EDUCACAO_FISICA/artigos/genero_ aulas.pdf. Acesso em: 26 mar. 2015.

CHAER, G.; DINIZ, R. R. P.; RIBEIRO, E. A. $A$ técnica do questionário na pesquisa educacional. Evidência, Araxá, v. 7, n. 7, p. 251-266, 2011. Disponível em: http://www.educadores.diaadia. pr.gov.br/arquivos/File/maio2013/ sociologia_artigos/pesqusia_social.pdf. Acesso em: 13 ago. 2015.

CORREIA, M. C. B. A observação participante enquanto técnica de investigação. Pensar Enfermagem, Lisboa, v. 13 n. 2, $2^{\circ}$ semestre de 2009. Disponível em: http://pensarenfermagem.esel.pt/ files/2009_13_2_30-36.pdf. Acesso em: 30 abr. 2015.

CRUZ, M. M. S.; PALMEIRA, F. C.C. Construção de identidade de gênero na Educação Física Escolar. Motriz, Rio Claro, v.15, n.1, p.116-131, jan./mar. 2009. Disponível em: http://boletimef. org/biblioteca/2425/artigo/BoletimEF. org_Construcao-de-identidade-degenero-na-Educacao-Fisica-escolar.pdf. Acesso em: 26 mar. 2015.

DELGADO, D.M.; PARANHOS, T.L. Fatores que levam a não participação das alunas nas aulas de educação física escolar no ensino médio. Orientado por Profo Dr José Antonio Viana. Rio de Janeiro, 2009. 29 f. Monografia (Licenciatura em Educação Física). Universidade Estácio de Sá, Rio de Janeiro, 2009. Disponível em: http:// boletimef.org/biblioteca/2677/tcc/ BoletimEF.org_Fatores-que-levam-anaoparticipacao-nas-aulas-de-EducacaoFisica.pdf. Acesso em: 30 agos. 2015.

DORNELLES, P. G. Marcas de gênero na Educação Física Escolar: a separação de meninos e meninas em foco. 
Motrivivência, Florianópolis, v.23, n.37, p.12-29, Dez. 2011. Disponível em: https://periodicos.ufsc.br/index. php/motrivivencia/article/view/21758042.2011v23n37p12/21752. Acesso em: 18 mar. 2015.

DUARTE, C. P.; MOURÃO, L. Representações de adolescentes femininas sobre os critérios de seleção utilizados para a participação em aulas mistas de Educação Física. Movimento, Porto Alegre, v.13, n. 01, p.37-56, jan./ abr. 2007. Disponível em: http://www. seer.ufrgs.br/index.php/Movimento/ article/view/2924/1558. Acesso em: 26 mar. 2015.

DUARTE, R. Entrevistas em pesquisas qualitativas. Educar, Curitiba, n. 24, p. 213-225, 2004. Disponível em: http:// www.scielo.br/pdf/er/n24/n24a11.pdf. Acesso em: 30 abr. 2015.

FERREIRA, N. S. C.; GRAHL, M.R. A produção científica de currículo no Brasil e as políticas curriculares: tendências e desafios, [s. I.], [s. d.]. Disponível em: http://www.anpae. org.br/iberoamericano2012/Trabalhos/ NauraSyriaCarapetoFerreira_GT2\%20. pdf. Acesso em: 29 abr. 2015.

FISCHER, R. M. B. Foucault e a análise do discurso em educação. Cadernos de Pesquisa, Rio Grande do Sul, n. 114, p. 197-223, nov. 2001. Disponível em: http://www.scielo.br/pdf/cp/n114/ a09n114.pdf. Acesso em: 13 ago. 2015.

GOMES, M. E. S.; BARBOSA, E. F. A técnica de grupos focais para obtenção de dados qualitativos. Educativa - Instituto de Pesquisas e Inovações Educacionais, Belo Horizonte, publicação interna, fev. 1999. Disponível em: http:// www.tecnologiadeprojetos.com.br/ banco_objetos/\% 7B9FEA090E-98E949D2-A638-6D3922787D19\% 7D

Tecnica $\% 20$ de $\% 20$ Grupos $\% 20$ Focais\%20pdf.pdf. Acesso em: 30 abr. 2015.

JESUS, M. L.; DEVIDE, F. P. Educação física escolar, co-educação e gênero: mapeando representações de discentes. Movimento, Porto Alegre, v.12, n. 03, p. 123-140, set./dez. 2006. Disponível em: http://www.seer.ufrgs.br/index.php/ Movimento/article/view/2912/1548. Acesso em: 26 mar. 2015.

LERVOLINO, S. A.; PELICIONI, M. C. F.A utilização do grupo focal como metodologia qualitativa na promoção da saúde. Revistada Escola de Enfermagem da USP, São Paulo, v. 35, n. 2, p. 115-21, jun. 2001. Disponível em: http://www.scielo.br/pdf/reeusp/v35n2/ v35n2a03. Acesso em: 30 abr.2015.

LIMA, F. M.; DINIS, N. F. Corpo e gênero nas práticas escolares de Educação Física. Currículo sem Fronteiras, Paraná, v.7, n.1, p.243-252, jan/ jun. 2007. Disponível em: http:// www.curriculosemfronteiras.org/ vol7iss 1articles/limadinis.pdf. Acesso em: 26 mar. 2015.

MARTINS, M. C. F. N.; BÓGUS, C. M. Considerações sobre a metodologia qualitativa como recurso para o estudo das ações de humanização em saúde. Saúde e Sociedade, São Paulo, v.13, n.3, p.44-57, set/dez. 2004. Disponível em: http://www.scielo. br/scielo.php?script =sci_arttext\&pid $=$ S0104-12902004000300006. Acesso em: 30 abr. 2015.

MELLO, D. F.; FIGUEIREDO, G. L. A.; NASCIMENTO, L. C. A utilização da técnica de vídeogravação em 
investigação de enfermagem em saúde da criança. Revista Brasileira de Enfermagem, Brasília - DF, v.56, n.2, p. 175-177, mar/abr.2003. Disponível em: http://www.scielo.br/pdf/reben/ v56n2/a13v56n2.pdf. Acesso em: 12 ago. 2015.

MELO, I. F. Análise do discurso e análise crítica do discurso: desdobramentos e intersecções. Revista Eletrônica de Divulgação Científica em Língua Portuguesa, Linguística e Literatura, São Paulo, ano 05, n. $11,2^{\circ}$ semestre de 2009. Disponível em: http://www. letramagna.com/adeacd.pdf. Acesso em: 13 ago. 2015.

NEVES, V. F. A. Pesquisa-ação e etnografia: caminhos cruzados. Pesquisas e Práticas Psicossociais, São João Del-Rei, v. 1, n. 1, jun.2006. Disponivel em: http:// www.ufsj.edu.br/portal-repositorio/ File/revistalapip/Pesquisa-Acao_e_ Etnografia...__-_VFA_Neves.pdf. Acesso em: 30 abr. 2015.

NOGUEIRA, M. S.; RODRIGUES, A. M. S. Meninos, meninas ou todo mundo junto? A questão do gênero nas aulas de educação física nas escolas da região sudeste da rede Pública municipal de Teresina. In: III Encontro de Educação Física e Áreas Afins. Núcleo de Estudo e Pesquisa em Educação Física (NEPEF) / Departamento de Educação Física / UFPI, ANAIS... Teresina, p.1-6, out. 2008. Disponível em: http://www. ufpi.br/subsiteFiles/def/arquivos/files/ MENINOS, $\% 20$ MENINAS $\% 200 U \% 20$ TODO \% 20MUNDO\% 20JUNTO.pdf. Acesso em: 25 mar. 2015.

OLIVEIRA, A. A. B. Motivação para a prática esportiva: Programa Segundo Tempo, Região 16. EFDeportes.com, Revista
Digital. Buenos Aires, ano 15, n. 150, nov. 2010. Disponível em: http://www. efdeportes.com/efd150/motivacao-paraa-pratica-esportiva.htm. Acesso em: 30 abr. 2015.

QUEIROZ, D. T. et al. Observação participante na pesquisa qualitativa: conceitos e aplicações na área da saúde. Revista Enfermagem UERJ, Rio de Janeiro, v. 15, n. 2, p. 276-283, 2007. Disponível em: http://www.facenf.uerj. br/v15n2/v15n2a19.pdf. Acesso em: 30 abr. 2015.

RESENDE, M. S. Olhares sobre os corpos e a construção de "homens" e "mulheres" na escola. Motrivivência, Florianópolis, v.23, n.37, p.69-82, dez. 2011. Disponível em: https:// periodicos.ufsc.br/index.php/ motrivivencia/article/view/21758042.2011v23n37p69/21756. Acesso em: 26 mar. 2015.

SANTOS, V. C. Indícios de sentidos e significados de feminilidade e de masculinidade em aulas de Educação Física. Motriz, Rio Claro, v.16, n.4, p.841-852, out./dez. 2010. Disponível em: http://www.scielo.br/pdf/motriz/ v16n4/a04v16n4.pdf. Acesso em: 26 mar. 2015.

SIDONE, O. J. G. Análise Espacial do Conhecimento no Brasil: Parte 1 Produção Científica. Informações Fipe, São Paulo, dez. 2013. Disponível em: http://www.researchgate.net/ publication/277952703_Anlise Espacial_do_Conhecimento_no_Brasil Parte 1 Produo Cientfica. Acesso em: 29 abr. 2015.

SILVA, P.; GOMES, P. B.; QUEIRÓS, P. Educação Física, Desporto e Género: o caminho percorrido na Faculdade 
de Desporto da Universidade do Porto (Portugal). Movimento, Porto Alegre, v.12, n. 01, p. 31-58, jan./abr. 2006. Disponível em: http://www.seer. ufrgs.br/index.php/Movimento/article/ view/2890/1526. Acesso em: 26 mar. 2015.

TAVARES, D. W. S. et al. Protocolo verbal e teste de associação livre de palavras: perspectivas de instrumentos de pesquisa introspectiva e projetiva na ciência da informação. Ponto de Acesso, Salvador, v.8, n.3, p. 64-79, dez. 2014. Disponível em: http://www. portalseer.ufba.br/index.php/revistaici/ article/view/12917/9240. Acesso em: 30 abr. 2015.

TEIXEIRA, F.A.; FOLLE, A. Participação dos alunos do ensino fundamental nas aulas de educação física: um estudo de caso. Educação Física em Revista, Brasília, v. 7, n. 2, p. 84-92, out. 2013. Disponível em: http://portalrevistas.ucb.br/index. php/efr/article/viewFile/3642/3047. Acesso em: 18 mar. 2015.

TEIXEIRA, F. A. Educação física escolar: reflexões sobre as aulas de exclusão.
Motrivivência, Florianópolis, v. 21, n.32/33, p. 335-343, jun./dez. 2009. Disponível em: https://periodicos. ufsc.br/index.php/motrivivencia/ article/view/2175-8042.2009n3233p335/14129. Acesso em: 26 mar. 2015.

TEIXEIRA, F. A.; MOLETTA, A. F. Motivação nas aulas de Educação Física. In: X Congresso Nacional de Educação EDUCERE. I Seminário Internacional de Representações sociais, subjetividade e Educação - SIRSSE. Universidade Católica do Paraná, Curitiba, ANAIS... p. 12763-12770, nov. 2011. Disponível em: http://educere.bruc.com.br/ CD2011/pdf/5041_3450.pdf. Acesso em: 13 ago. 2015.

VIEIRA, K. F. L.; COUTINHO, M. P. L. Representações Sociais da Depressão e do Suicídio Elaboradas por Estudantes de Psicologia. Psicologia Ciência e Profissão, Brasília, v. 28, n.4, p. 714-727, abr. 2008. Disponível em: http://www.scielo.br/pdf/pcp/v28n4/ v28n4a05.pdf. Acesso em: 30 abr. 2015.

\section{DISCUSSION OF GENDER IN PHYSICAL EDUCATION CLASSES: a systematic review}

\section{ABSTRACT}

The aim of this study was to verify through systematic review the implications of the possible participation or / non-participation of girls in physical education classes. It is a systematic literature review conducted in CAPES Journal Portal databases and Lilacs, and in scientific journals Motrivivência and Physical Education Magazine. Initially it found a total of 260 articles, analyzed which have been titles, abstracts, and later the full article, only 07 being selected articles. Therefore, us articles selected there is a strong built influence historically and rooted in society about girls' participation in physical education classes, these are considered less skilled for sports compared to boys, society, as well as school end up further enhance this male superiority.

Keywords: Gender; Physical Education; School 
V. $28, n^{\circ} 47$, maio/2016

DISCUSIÓN DE GÉNERO EN LAS CLASES DE EDUCACIÓN FÍSICA: una revisión sistemática

\section{RESUMEN}

El objetivo de este estudio fue verificar mediante la revisión sistemática de las implicaciones de la posible participación o / no participación de las niñas en las clases de educación física. Es una revisión sistemática de la literatura realizada en las bases de datos CAPES Diario Portal y Lilacs, y en revistas científicas Motrivivência y Revista de Educación Física. Inicialmente se encontró un total de 260 artículos, que han sido analizado minuciosamente títulos, resúmenes y el artículo completo, sólo el 07 seleccionándose artículos. Por lo tanto, los artículos seleccionados una fuerte influencia construido históricamente y arraigados en la sociedad acerca de la participación de las niñas en las clases de educación física, estos son considerados menos capacitados para los deportes en comparación con los varones, y la sociedad, así como la escuela acabar mejorar aún más esta superioridad masculina.

Palabras clave: Género; Educación Física; Escuela

Recebido em: outubro/2015 Aprovado em: abril/2016 